\title{
SAPIENS PARQUE E O TURISMO DE NEGÓCIOS EM FLORIANÓPOLIS \\ Produção do espaço urbano e turismo de negócios no setor de alta tecnologia ${ }^{1}$
}

\section{SAPIENS PARK AND BUSINESS TOURISM IN FLORIANÓPOLIS \\ Production of urban space and business tourism in the high technology sector}

\author{
A. Aline V. Cavanus \& B. Tomas C. Massabki \\ Universidade de São Paulo, Brasil \\ aline.cavanus@usp.br \\ tomas.massabki@usp.br
}

\begin{abstract}
RESUMO
O turismo é uma importante atividade econômica e produtiva, entendida na perspectiva da produção do espaço enquanto mercadoria, já que seu objeto de consumo é o espaço mercantilizado. A Sociedade de Propósitos Específicos Sapiens Parque S.A foi criada em 2002 e está atualmente em implantação. Sua atuação se dá principalmente na área de alta tecnologia, além da saúde (farmacologia) e do turismo (centros de eventos). O presente artigo debate como esse projeto contribui com a produção do espaço por meio do turismo de negócios. O objetivo deste artigo é analisar a relação entre o turismo de negócios e o setor de alta tecnologia na produção do espaço urbano em Florianópolis-SC, por meio do projeto Sapiens Parque, usando a metodologia de estudo de caso. O Sapiens Parque cumpre importante papel como vetor desse tipo de turismo, por meio de parcerias entre agentes públicos e privados e criação de infraestruturas.
\end{abstract}

Palavras-chave: produção do espaço, turismo de negócios, Florianópolis, Sapiens Parque Linha de Investigação: 3: Dinâmicas Urbanas

Tópico: Turismo

\section{ABSTRACT}

Tourism is an important economic and productive activity, under the perspective of production of space as a commodity, because its consumption object is commodified space. The Sociedade de Propósitos Específicos Sapiens Parque S.A was created in 2002 and is under implantation. Its activities are mainly at high technology, as well as health (with pharmacology) and tourism (with the creation of event center). The present paper debates how this project relates to production of commodified space through business tourism. The

\footnotetext{
${ }^{1}$ Este artigo foi construído como parte de pesquisa de mestrado financiada pela Fundação de Amparo à Pesquisa do Estado de São Paulo (FAPESP), processo oำ 2018/19089-5.
} 


\section{SÃOPAULO15 $\quad$ S $17 \cdot$ LISBOA $25 \sim 26$ JUN 2020}

objective of this paper is to analyze the relation between the business tourism and high technology sector on the production of urban space in Florianópolis-SC, through the Sapiens Park project, using the study of case methodology. Sapiens Park fulfills an important role as a vector of this type of tourism, through association between public and private agents and creation of infrastructure.

Keywords: production of space, business tourism, Florianópolis, Sapiens Park

Research line: 3: Urban dynamics

Topic: Tourism

\section{Introdução}

A construção desse artigo parte da compreensão do turismo na produção do espaço enquanto mercadoria, trabalhando com a metodologia de estudo de caso para melhor apreensão do fenômeno estudado. $\mathrm{Na}$ pesquisa se estuda o projeto Sapiens Parque em Florianópolis-SC e suas relações com o turismo de negócios. Trabalha-se com o método hipotético-dedutivo, tendo um caráter teórico e empírico. A hipótese é que esse projeto se relaciona com a produção do espaço mercantilizado por meio do turismo de negócios, processo empreendido por agentes dos setores público e privado. Por meio de pesquisa bibliográfica e documental e de trabalho de campo, pretende-se apurar a validade dessa hipótese. O objetivo do artigo é analisar a relação entre o turismo de negócios e o setor de alta tecnologia na produção do espaço urbano em Florianópolis, por meio do projeto Sapiens Parque, entendendo a dinâmica de inserção dessa cidade no panorama do turismo de negócios brasileiro, analisando os aspectos presentes no projeto Sapiens Parque relacionados a esse setor e compreendendo de que forma o projeto se insere na produção do espaço em Florianópolis.

\section{Turismo no processo de produção do espaço}

O turismo, enquanto fenômeno importante na dinâmica espacial e urbana, é também uma área de estudos com dificuldades metodológicas e conceituais. Se em seus primórdios foi vinculado à noção de lazer, no decorrer do século XX passou a se confundir com o conceito de viagem, entendimento que, de certa forma, inflacionou as estatísticas oficiais referentes a essa área (Cruz, 2007).

Mais do que uma somatória de deslocamentos de pessoas, o turismo pode ser entendido como uma atividade econômica e produtiva, participando do processo de produção social do espaço por meio do seu uso turístico. Compreender que o turismo converte o espaço em mercadoria, que passa a ser apropriada privadamente e produzida para o consumo da atividade turística (Carlos, 2007; Cruz, 2007) é fundamental para dimensionar a influência que essa atividade exerce na produção do espaço. No âmbito urbano, "a urbanização turística coloca as cidades no mercado de paisagens naturais e artificiais. Algumas cidades chegam a redefinir toda sua vida econômica em função do desenvolvimento turístico, reorganizando-se para produzir paisagens atrativas para o consumo e para o lazer" (Luchiari, 1998: 17).

Neste processo de apropriação de porções do espaço para essa atividade, diferentes agentes participam, cada qual com seus próprios interesses nessa produção. Destaca-se o papel de normatização do setor turístico e da construção de infraestruturas, protagonizado pelo Estado; as empresas privadas, especialmente da área de hotelaria, restaurantes, bares, companhias aéreas, mais recentemente envolvidas 


\section{SÃO PAULO15 17 LISBOA $25 \sim 26$ JUN 2020}

em uma rede internacional de financeirização característica do neoliberalismo; os turistas, cuja origem remete a diferentes espaços emissores, cada um dos quais influenciando na atividade turística e, consequentemente, na produção do espaço apropriado por ela; e os moradores do espaço receptor, cuja relação com o turismo é complexa, indo desde uma postura passiva, passando por sua incorporação à atividade turística, até o papel de contraposição a essa hegemonia imposta (Cruz, 2007).

\subsection{Turismo de negócios e eventos: especificidades}

O turismo de negócios, por envolver o deslocamento de pessoas por motivo de trabalho, pode ser considerado um "turismo obrigatório", conforme aponta Yázigi (Cruz, 2007). Importante compreender que, segundo a autora, o turismo de eventos se distingue dos negócios porque eventos "são acontecimentos planejados que reúnem pessoas em um determinado espaço e tempo" (Braga apud Cruz, 2007: 44). Ainda que se relacionem, o primeiro é marcado por se beneficiar de um desenvolvimento econômico anterior ao turismo, não podendo os agentes desse setor criarem um espaço receptor de turismo de negócios, o que pode ser feito para o turismo de eventos (Cruz, 2007). Considerando tal distinção, cabe pontuar que, no presente trabalho, consideraremos o turismo de negócios e de eventos (a seguir nomeado apenas como "turismo de negócios") como um único segmento, já que é esse o tratamento dado pelos órgãos oficiais em suas estatísticas e porque essa classificação faz sentido no contexto do presente trabalho. Ainda assim, essa diferenciação traz importantes contribuições teóricas para a compreensão do papel do turismo na produção social do espaço.

Sob essa perspectiva, cabe compreender a especificação do turismo de negócios, considerando que-esse segmento tem apresentado queda na proporção de turistas vindos para o Brasil entre 2012 e 2016 (de 25,3\% para 18,7\%), mas também que são esses turistas que mais gastam por dia de estadia (em 2016, gastaram per capita por dia US\$ 82,54, frente aos US\$ 61,41 dos turistas de lazer e os US\$ 39,92 para visitantes por outros motivos) (Ministério do Turismo, 2018). Desses dados se infere a motivação econômica da seguinte afirmação do Ministério do Turismo (MTur) presente no último Plano Nacional de Turismo (PNT), válido para 2018-2022: "é preciso intensificar as ações para retomar a participação do Brasil no mercado internacional de eventos" (MTur, 2018: 33)².

Cabe compreender, também, que o segmento do turismo de negócios não pode ser isolado de um contexto geral de turismo. Se, em muitos casos, o turismo de negócios se dá por um uso turístico do deslocamento de pessoas envolvidas em uma atividade econômica anteriormente desenvolvida, em outros casos, ele se desenvolve em espaços receptores tipicamente ligados ao turismo de lazer, como aponta Ferreira (2010: 33) ao estudar São Luís-MA: "Apesar do turismo de negócios ocorrer muito em centros urbanos e industrializados, ele ocorre também em outros destinos, inclusive aqueles voltados ao lazer como é o caso de São Luís". O mesmo já vem ocorrendo em Florianópolis, como no exemplo do Costão do Santinho Resort, apontado por Válio (2004). Ainda assim, para a ocorrência do turismo de negócios, é necessário que haja, para além da infraestrutura hoteleira e de espaços de eventos, uma atividade econômica relevante e internacionalizada.

2. lo material do PNT, não há distinção entre turismo de negócios e turismo de eventos, sendo ambos compreendidos como "turismo de negócios e eventos". 


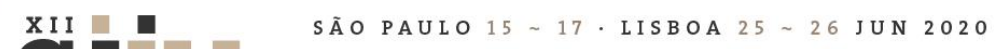

Quanto ao papel de Florianópolis no cenário do turismo de negócios e eventos, a cidade consta como a $5^{\underline{a}}$ dentre as brasileiras e $272^{a}$ no mundo todo, a frente de metrópoles brasileiras como Belo Horizonte, Porto Alegre e Curitiba, segundo a International Congress and Convention Association (ICCA, 2019).

\section{Florianópolis: caracterização geral}

Florianópolis, capital do estado de Santa Catarina e sede de Região Metropolitana de Florianópolis, tem população estimada em 500.973 habitantes (IBGE, 2019a). A Região Metropolitana, composta por 22 municípios e abrigando uma população estimada de 1.209.818 habitantes (IBGE, 2019b), abarca também um processo de conurbação entre a capital e as cidades de Palhoça, Biguaçu e São José, constituindo o que é chamada de Área Conurbada de Florianópolis (ACF), parte do núcleo metropolitano da Região Metropolitana, que também é dividida em área de expansão (conforme figura 01). A ACF pode ser considerada peculiar por conta de grande parte de seu território ser insular, além de seu marcante patrimônio natural (Kronenberger \& Saboya, 2019), constantemente explorado na construção da imagem de "Ilha da Magia", elemento recorrente e distintivo da atividade turística da região (Lenzi, 2016).

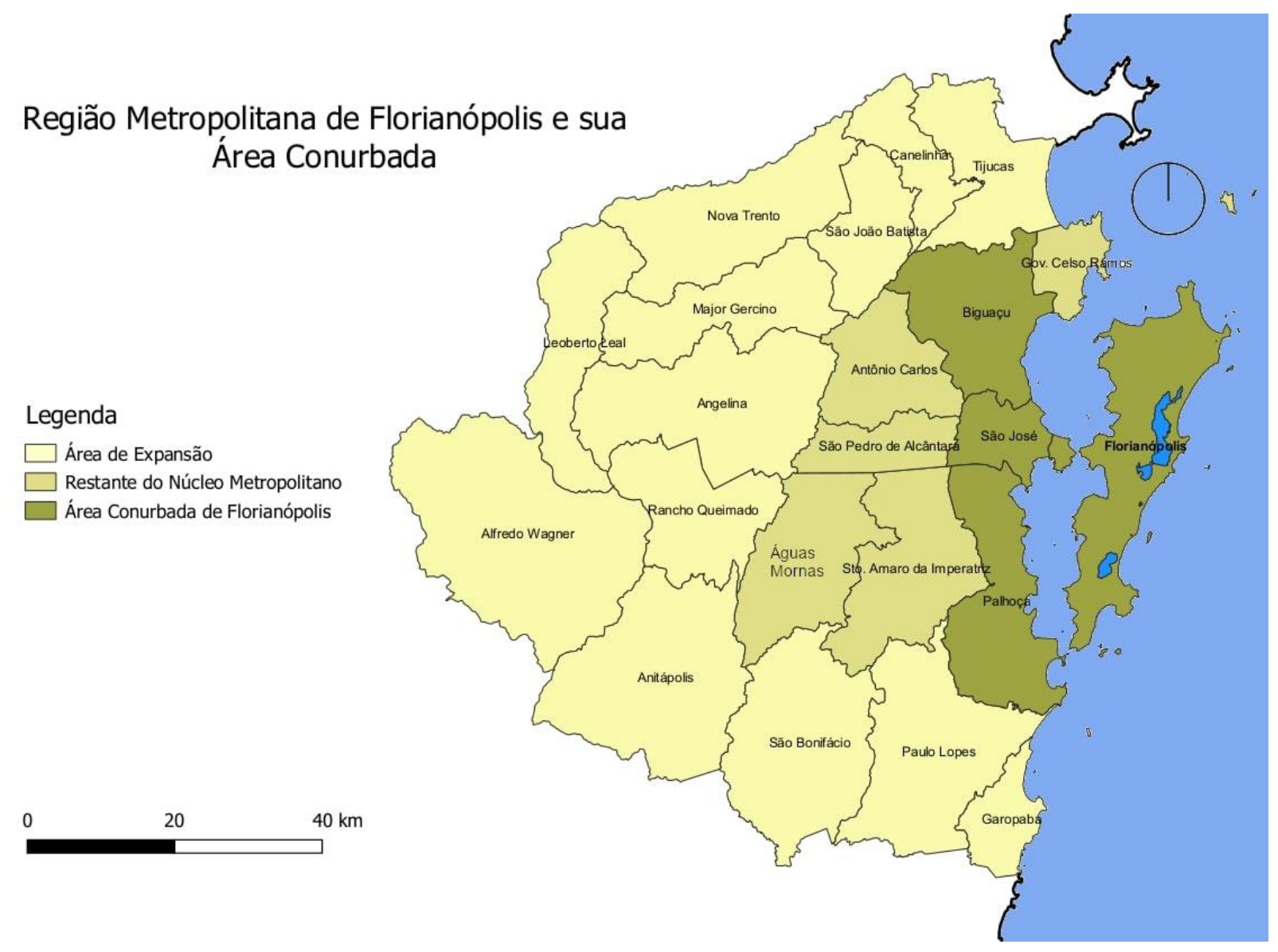

Figura 01: Região Metropolitana de Florianópolis e sua Área Conurbada. Elaboração própria a partir de dados da LCE 495/2010 de Santa Catarina (Santa Catarina, 2010) 


\section{SÃOPAULO15 17 LISBOA $25 \sim 26$ JUN 2020}

\subsection{Características urbanas e econômicas}

Em Florianópolis, a colonização de grupos açorianos é outro elemento característico, contribuindo para a presença constante de malhas em "espinha de peixe" e servidões, organização viária contrastante com a malha ortogonal, de origem mais recente e ligada ao uso do solo por empreendimentos turísticos e residenciais de alta renda (Kronenberger \& Saboya, 2019).

O processo de conurbação entre a capital e os municípios de Palhoça, Biguaçu e São José é expresso, por um lado, por sua interdependência socioeconômica e por desdobramentos socioespaciais, por outro lado. Esse processo permite entender que os quatro municípios "constituíam efetivamente um único espaço intraurbano" (Sugai, 2015: 29).

Florianópolis, mesmo possuindo uma porção continental, tem seu território majoritariamente localizado na Ilha de Santa Catarina (97,23\%), marcada pela presença de diversas lagoas, cadeias de morros em sua extensão norte-sul e dezenas de praias ao redor de seu litoral, formações naturais que influenciam na rede viária do município e em suas atividades econômicas.

A economia da cidade se caracteriza por uma predominância do setor de serviços, com este representando $45,58 \%$ dos empregados, seguido por $32,37 \%$ na administração pública, $14,47 \%$ no comércio, 3,20\% na construção civil, 2,21\% na indústria de transformação, 2,01\% nos serviços industriais de utilidade pública, 0,13\% na agropecuária e míseros 0,03\% em extrativa mineral (Secretaria do Estado da Fazenda, 2012). Percebe-se, assim, a importância que o setor terciário tem na economia da cidade, com mais de $90 \%$ dos empregados. Cabe ressaltar que é nesse grupo que se situam aqueles que trabalham com o turismo e o com o setor de alta tecnologia, duas áreas características da economia florianopolitana.

\section{2. "Ilha da Magia": cidade turística em competitividade neoliberal}

Em um contexto de competitividade neoliberal, que coloca as cidades nas disputas por mercados, Florianópolis tem sido divulgada como uma cidade de desenvolvimento sustentável e qualidade de vida (Sugai, 2015). Uma concepção baseada na gestão da cidade como uma empresa, na qual o desenvolvimento é consequência da boa gestão do governo local, e em que seu bom desenvolvimento se espalharia para todas as camadas sociais, sem a devida atenção à pobreza e desigualdade social (Sugai, 2015).

Assim, a cidade é vendida de acordo com os seus atributos, como espaços de convenções, parques tecnológicos, torres de comunicação ou infraestrutura para os negócios (Vainer, 2000). Aparecendo muito mais pelo seu valor de troca, numa disputa internacional, devido aos capitais financeiros, na qual essas cidades competem pelos investimentos, sendo o setor do turismo um importante vetor dessa dinâmica.

O Programa de Regionalização do Turismo, realizado pelo MTur em conjunto com as unidades federadas, tem como principais produtos a categorização dos municípios brasileiros pertencentes a alguma região turística (MTur, 2015) e a consequente organização dos mesmos no Mapa do Turismo Brasileiro. Esta categorização do desempenho da economia do turismo, variando de $\mathrm{A}$ a $\mathrm{E}$, se baseia em cinco variáveis: quantidade de estabelecimentos de hospedagem, quantidade de empregos em estabelecimentos de hospedagem, quantidade estimada de visitantes domésticos, quantidade estimada de visitantes internacionais e arrecadação de impostos federais a partir dos meios de hospedagem (MTur, 2019b). 


\section{SÃOPAULO15 $\quad$ S $17 \cdot$ LISBOA $25 \sim 26$ JUN 2020}

Nota-se, conforme indica a figura 02 , o destaque da cidade de Florianópolis, em categoria A, especialmente em relação a sua Área Conurbada, já que tanto São José quanto Biguaçu não constam no Mapa do Turismo Brasileiro, ainda que Palhoça se situe em categoria B nessa classificação.

Esse destaque não é exclusivo do contexto da Região Metropolitana de Florianópolis. Dentre as capitais de estados brasileiros, a capital catarinense possui a maior rede de hospedagem em proporção a sua população, com 65 estabelecimentos, 2.353 unidades habitacionais e 6.455 leitos a cada 100.000 habitantes; estes dados também destoam na escala estadual, já que Santa Catarina apresenta 26 estabelecimentos, 819 unidades habitacionais e 2.125 leitos por 100.000 habitantes; na escala macrorregional, pois a região Sul comporta 19 estabelecimentos, 615 unidades habitacionais e 1.477 leitos por 100.000 habitantes; e, por fim, no contexto nacional, considerando que o Brasil tem 15 estabelecimentos, 491 unidades habitacionais e 1.168 leitos a cada 100.000 (IBGE, 2017).

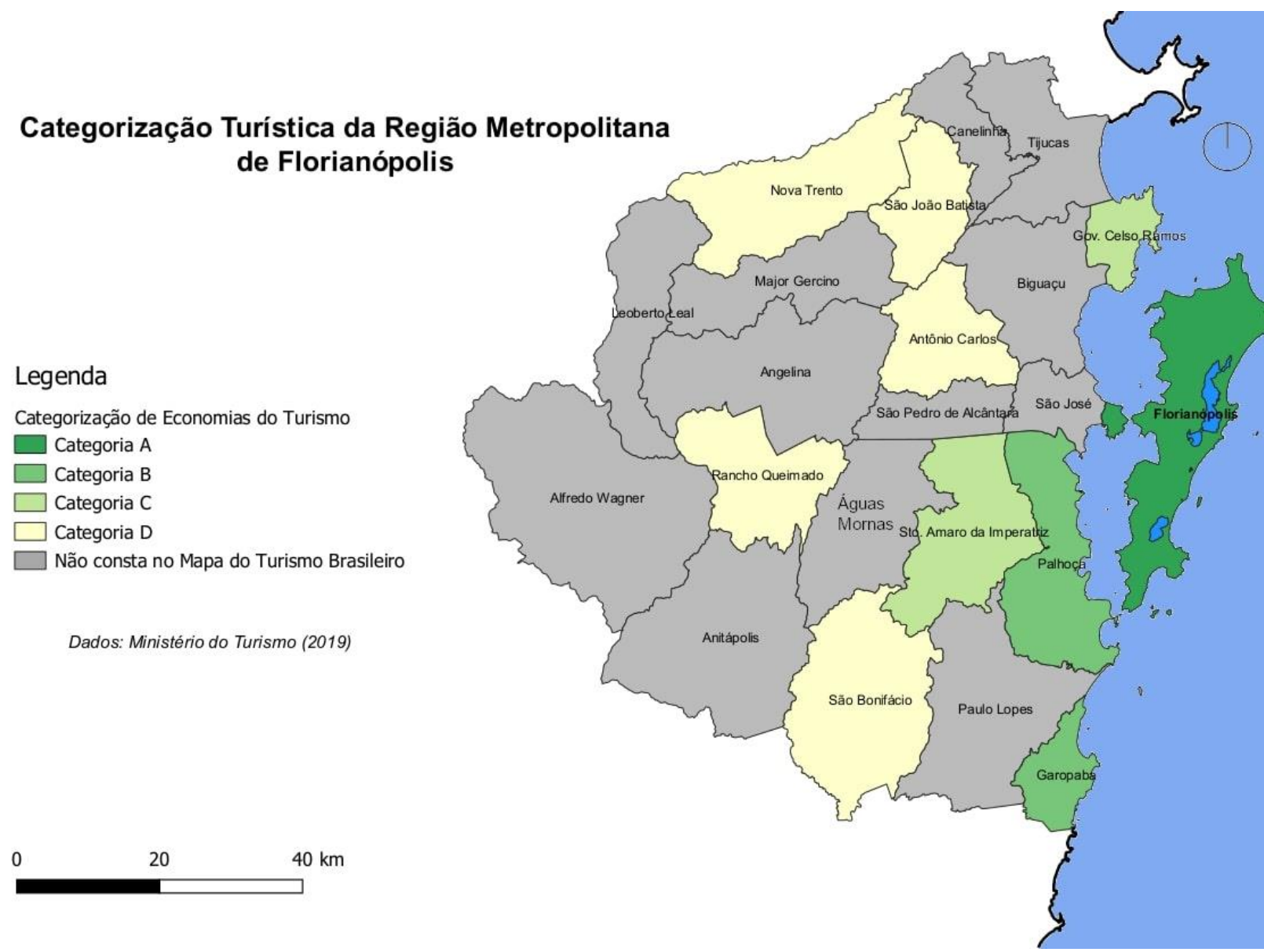

Figura 02: Categorização Turística da Região Metropolitana de Florianópolis. Elaboração própria a partir de dados da Categorização 2019/2021 do Mapa do Turismo Brasileiro (MTur, 2019a)

Considerando a proporção de hospedagem por habitante em Florianópolis e a importância do setor de serviços em suas atividades econômicas, é notável que a produção social do uso turístico do espaço na cidade logrou resultados. As ações conjuntas entre agentes públicos e privados, visando fazer do turismo não só a principal atividade econômica, mas também sua vocação enquanto cidade, datam desde a década 


\section{SÃO PAULO15 17 LISBOA $25 \sim 26$ JUN 2020}

de 1950 (Oliveira, 2011). Essa suposta vocação turística, construída ao longo de todo o século XX por esses agentes, passa por problemas, como a sazonalidade e o baixo retorno financeiro de segmentos do turismo (Lenzi, 2016).

O turismo de negócios surge para solucionar ou ao menos mitigar esses efeitos negativos. Além do maior poder aquisitivo nesse perfil de turista, este pode ser um fator de diminuição da sazonalidade, marcante aspecto com consequências negativas para a economia da cidade. Como nos mostra Lenzi (2016: 128-129):

Já com relação à segmentação e ao combate à sazonalidade, Funcionário (informação verbal) afirma que esse centro de eventos deve trazer um novo cenário para o turismo em Florianópolis, pois vai começar a diversificar os segmentos, não mais ficando o turismo restrito a "sol e mar" pois, para ele, esse foco quase que exclusivo acarretou efeitos negativos para a cidade e para o estado

Além disso, se percebe uma tendência da região norte receber as infraestruturas necessárias para esse segmento do turismo, pois "em 2015, deve ser inaugurado mais um centro de eventos na llha ${ }^{113}$, em Canasvieiras. A sua localização deve-se a uma análise mercadológica que vislumbra para aquela região a criação de um cluster turístico" (Lenzi, 2016: 128). Essa tendência se corrobora também na projeção de uma rota da inovação entre o Aeroporto Hercílio Luz e o Sapiens Parque, conforme apontado na figura 03.

Nos anos 1960 o turismo aparece como um importante fator de desenvolvimento e construção de infraestruturas em Florianópolis. A Lei Municipal no 853/67, cria o Plano Municipal de Turismo - PMT e a Diretoria de Turismo e Comunicação e a Lei № 4.240/68 definia a política de Turismo para o estado, criando o Departamento Autônomo de Turismo do Estado de Santa Catarina - DEATUR. Também foi criado, em 1971, o BESC Empreendimentos e Turismo S/A, com o intuito de viabilizar créditos para investimentos no ramo do turismo. Os investimentos no turismo e interesses imobiliários também influenciaram o planejamento urbano de Florianópolis principalmente pós 1960, expresso em seus planos diretores, assim como a expansão urbana, Nacionalmente, no II Plano Nacional de Desenvolvimento - PND (1975-1979), o turismo seria um motor do desenvolvimento urbano de Florianópolis e de sua integração territorial, com investimentos públicos na malha viária, transporte público, infraestrutura de energia elétrica e de água encanada (Corrêa \& Pieruccini, 2017).

Por fim, Florianópolis é a primeira cidade brasileira a ser incluída no grupo de 69 cidades da Rede Mundial de Cidades Criativas da UNESCO, importante indicador da inserção da cidade no circuito internacional do turismo, com reconhecimento de órgãos oficiais internacionais (Ferreira, 2017). Cabe compreender, agora, de que forma o projeto do Sapiens Parque contribui para a formação desse cluster ${ }^{3}$ turístico e qual sua relação com o crescente setor de alta tecnologia na cidade, além das características consolidadas na formação urbana da cidade.

3. Cluster pode ser entendido como a concentração de empresas de um mesmo setor, envolvendo um agrupamento de atores empresariais e institucionais de diferentes segmentos, pue, mesmo em competição, trabalham em conjunto (participando de feiras ou dividindo fretes, por exemplo). Esse trabalho coletivo de empresas concorrentes faria crescer a produtividade das empresas locais, o que seria um incentivo à criação de negócios na área. (HOST\&TRAVEL, 2018) 


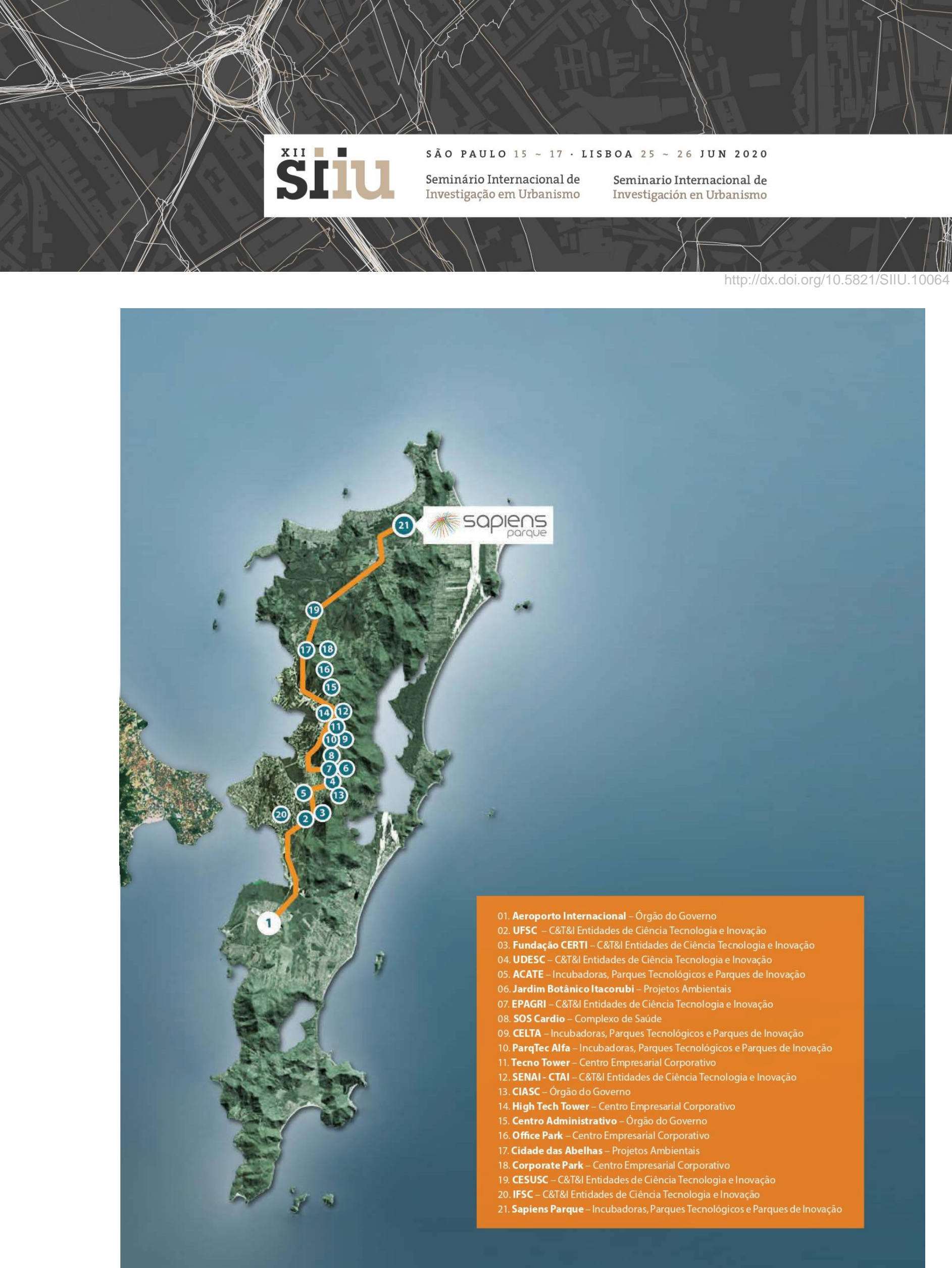

Figura 03: Rota da inovação, indicando principais infraestruturas dos setores de Ciência, Tecnologia e Inovação e centros empresariais corporativos, com destaque para o Aeroporto Internacional Hercílio Luz e o Sapiens Parque. Fonte: (Sapiens Parque, 2018). 


\section{SÃOPAULO15 17 LISBOA $25 \sim 26$ JUN 2020}

\section{O projeto Sapiens Parque}

No norte da llha de Santa Catarina, área de expansão do setor de tecnologia, o Grupo Sapiens Parque tem construído um parque empresarial de inovação tecnológica, apoiado pela Fundação CERTI - Centro de Referência em Tecnologias Inovadoras (Silva, 2011).

Segundo o material de divulgação do Sapiens Parque o local seria uma conjunção entre arte, ciência e meio ambiente em um espaço de inovação. Lá existiria a infraestrutura necessária para o desenvolvimento econômico, social, tecnológico e ambiental, por meio do conceito de Parque de Inovação e da sustentabilidade e competitividade (Sapiens Parque, 2018).

Ciência e tecnologia, meio ambiente e turismo são palavras-chave que aparecem nos diferentes meios de comunicação que tratam do empreendimento (Sapiens Parque, 2018; Carioni, 2017; FloripAmanhã, 2016; VIA, 2016). A infraestrutura urbanística em conjunto das características de apelo turístico de Florianópolis, assim como as parcerias público-privadas, são pontos centrais alinhados com a possibilidade de investimento imobiliário. Segundo o material de divulgação e artigo do grupo $\mathrm{VIA}^{4}$, a proposta segue um sistema "4x4" composto pelos Pilares (Scientia, Artis, Naturallium e Gens), os Clusters (Tecnologia, Turismo e Serviços), Estrutura (Urbanização, Região, Pessoas e Capital) e Atores (Governo, Empresas, Academia e Sociedade) (VIA, 2016). Os chamados Pilares se reúnem no objetivo de atrair capitais: a Scentia atrai as empresas de tecnologia, a Artis os espaços chamados criativos, a Naturallium os atrativos das praias e as chamadas "belezas naturais" e a Gens o capital humano. Esses diferentes pontos convergem numa proposta de mercado para Florianópolis que atrai um determinado tipo de pessoa que se fixará na cidade, na expectativa de negócios e qualidade de vida e um outro tipo de pessoa que visita para os eventos de negócios, com extensão para os atrativos naturais e culturais, em que a Estrutura é a base para essas ideias se materializarem e os Atores os responsáveis por executá-las.

A área total do empreendimento é de $4.315 .680,88 \mathrm{~m}^{2}$ (431,5 hectares), contando com 257 unidades (68 delas já comercializadas, segundo material de divulgação de 2018). O terreno onde é implantado o projeto é de propriedade do Governo de Santa Catarina e da Companhia de Desenvolvimento do Estado de Santa Catarina - CODESC, onde anteriormente funcionava a Colônia Penal Agrícola de Canasvieiras (Sá, 2004), nas margens da rodovia estadual SC-401 e fazendo divisa com os bairros de Canasvieiras, Cachoeira do Bom Jesus, Vargem do Bom Jesus e Vargem Grande, conforme indicado na figura 04.

4. O grupo VIA - Estação Conhecimento busca a integração entre academia, empreendedores, governo e sociedade e é ligado ao grupo de pesquisa do CNPq - Habitats de Inovação e Empreendedorismo, da Universidade Federal de Santa Catarina. (VIA, s/d) 


\section{S ÃO PAULO15 17 LISBOA $25 \sim 26$ JUN 2020 \\ Seminário Internacional de Seminario Internacional de Investigação em Urbanismo Investigación en Urbanismo}

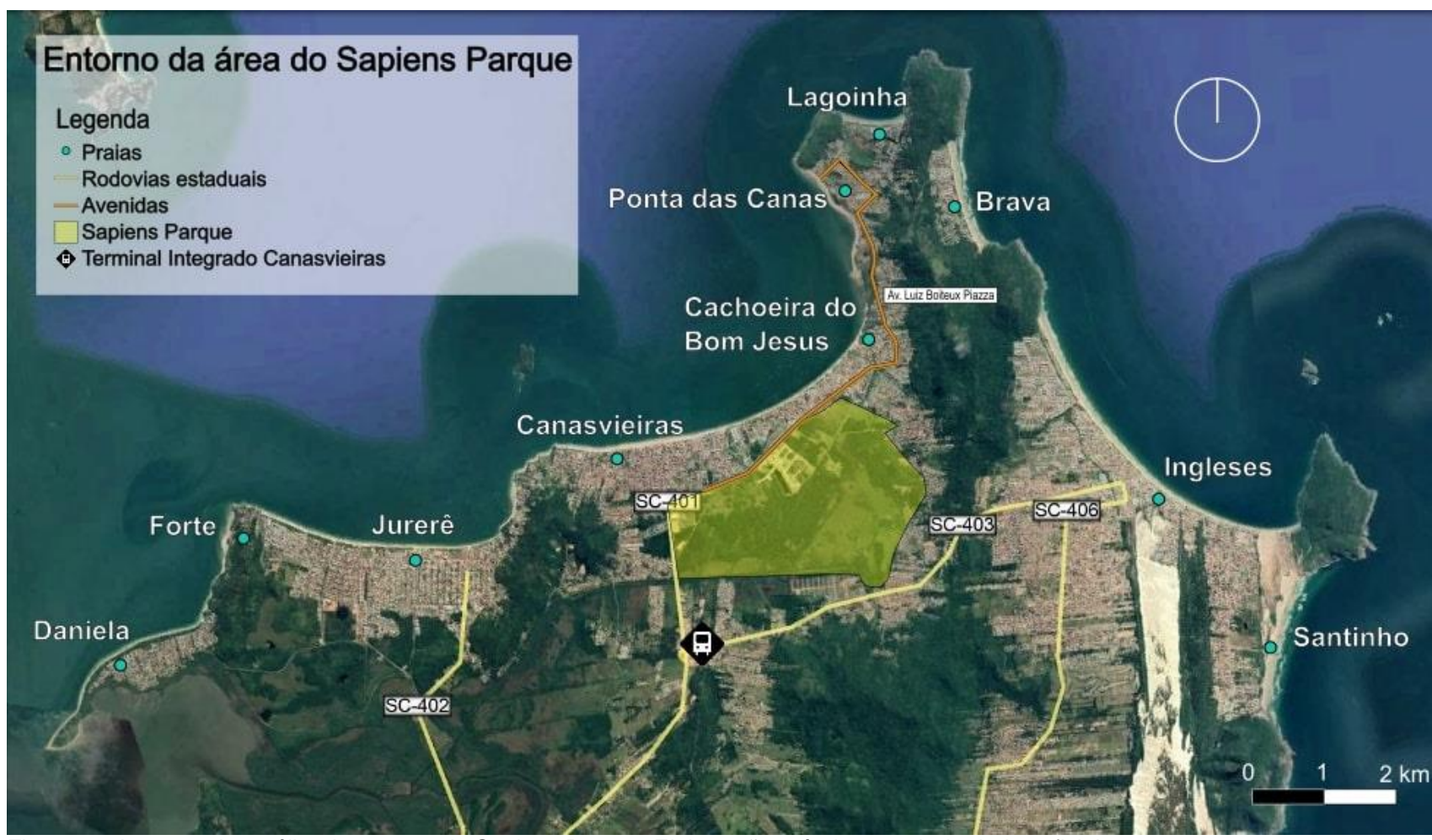

Figura 04: Imagem de satélite do entorno do Sapiens Parque. Elaboração própria a partir de dados oficiais

A "venda" da cidade de Florianópolis como um destino turístico, com qualidade de vida, lendas, resquícios coloniais e belas praias cria um imaginário que "agrega valor" ao produto e contribui nessa disputa por negócios, justificando o investimento na cidade. Ao longo do documento são mencionados dados, em que a cidade aparece como "A melhor para criar os filhos" e "A melhor para empreender" (Sapiens Parque, 2018). Essas caracterizações fazem parte de uma peça publicitária interessada em atrair investidores. As conexões com universidades públicas e demais entidades, assim como agências de fomento, dão credibilidade ao empreendimento. Dentre os apoiadores e parceiros do Sapiens Parque encontramos a UFSC - Universidade Federal de Santa Catarina, a UDESC - Universidade do Estado de Santa Catarina, a FIESC - Federação das Indústrias do Estado de Santa Catarina, a ACIF - Associação Comercial e Industrial de Florianópolis, a ACATE - Associação Catarinense de Tecnologia, a ABIH-SC - Associação Brasileira da Indústria de Hotéis de Santa Catarina, o CREA-SC, o SEBRAE-SC, a NSC TV, a Record TV, o BRDE - Banco Regional de Desenvolvimento do Extremo Sul, o Banco do Brasil, a Caixa, a Floripa Convention (Sapiens Parque, 2019), a fundação CERTI, as incubadoras ou parques tecnológicos ${ }^{5}$, como o ParqTec Alfa ${ }^{6}$, a ASSESPRO-SC Associação das Empresas Brasileiras de Tecnologia da Informação, Software e Internet, o CETIC-SC Conselho das Entidades de Tecnologia da Informação e Comunicação de Santa Catarina, o SEPD Sindicato das Empresas de Informática e Processamento de Dados da Região Metropolitana de

5. O conceito de parque tecnológico está relacionado à concentração geográfica de diferentes empresas do ramo da tecnologia, assim como instituições de ensino, centros de pesquisa, laboratórios e incubadoras. Esses parques buscam promover a integração e a competitividade entre as empresas, assim como a inovação. (Carioni, 2017)

6. O ParqTec Alfa abriga atualmente mais de 60 empresas e é localizado às margens da SC-401. (Carioni, 2017) 


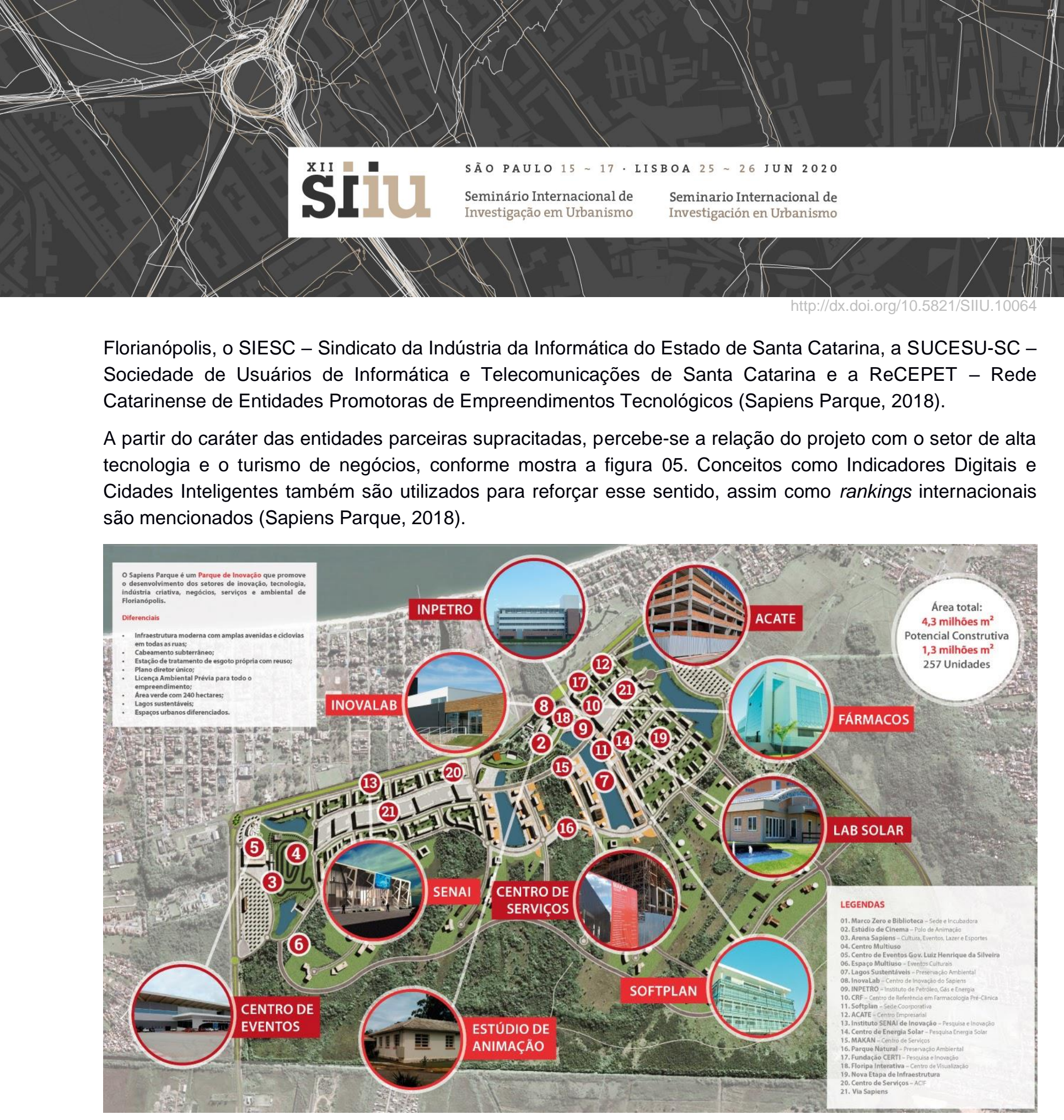

Florianópolis, o SIESC - Sindicato da Indústria da Informática do Estado de Santa Catarina, a SUCESU-SC Sociedade de Usuários de Informática e Telecomunicações de Santa Catarina e a ReCEPET - Rede Catarinense de Entidades Promotoras de Empreendimentos Tecnológicos (Sapiens Parque, 2018)

A partir do caráter das entidades parceiras supracitadas, percebe-se a relação do projeto com o setor de alta tecnologia e o turismo de negócios, conforme mostra a figura 05. Conceitos como Indicadores Digitais e Cidades Inteligentes também são utilizados para reforçar esse sentido, assim como rankings internacionais são mencionados (Sapiens Parque, 2018).

Figura 05: Divulgação do Parque de Inovação do Sapiens Parque pela Fundação CERTI. Fonte: (Carioni, 2017)

Cabe também ressaltar os incentivos fiscais dados ao parque, sendo os estaduais principalmente relacionados ao Imposto Sobre Circulação de Mercadorias e Serviços - ICMS, e os municipais sobre Imposto Predial e Territorial Urbano - IPTU e o Imposto Sobre Serviços - ISS, o que aumenta a competitividade e atratividade da área (Sapiens Parque, 2018).

O grupo FloripAmanhã7, em material produzido no ano de 2016, lança o projeto "Floripa 2030 - Agenda Estratégica de Desenvolvimento Sustentável de Florianópolis na Região". Nesse material são elaboradas 5

7. FloripAmanhã é uma Organização da Sociedade Civil de Interesse Público - OSCIP, que congrega pessoas físicas e jurídicas, fundada em 2005, com o objetivo de atuar no desenvolvimento econômico, social e ambiental da Grande Florianópolis, difundindo a cultura do planejamento e do desenvolvimento urbano, estimulando a cooperação público-privada e apoiando a vocação turística e 


\section{SÃOPAULO15 17 LISBOA $25 \sim 26$ JUN 2020}

estratégias para o desenvolvimento da cidade. Os projetos Sapiens Parque e Centro Sapiens (proposta parceira para o centro da cidade) aparecem como integrantes da estratégia 2: Cidade Multicultural e Polinucleada, na qual o Sapiens Parque cumpre o papel de nova centralidade no norte da llha (FloripAmanhã, 2016). Além disso, no mesmo documento, vemos menções ao Sapiens Parque na estratégia 1 - Florianópolis Sinônimo de Qualidade, em que o Sapiens Parque aparece como exemplo de projeto exitoso de parceria entre políticas públicas e iniciativa privada no desenvolvimento científico e tecnológico. (FloripAmanhã, 2016).

Todos esses elementos apontam para o fato de que o projeto Sapiens faz parte de uma rede de parceiros que externalizam um projeto de cidade. A fundação CEPA, responsável pelo Master Plan do Sapiens Parque, foi também responsável pelo Plano Diretor de Florianópolis e de iniciativas como Jurerê Internacional (Fundación CEPA, 2017). Vemos assim, diferentes grupos, reunidos num projeto que envolve o setor imobiliário, hotelaria e serviços, gastronomia, alta tecnologia, turismo e negócios.

No material de divulgação do Sapiens Parque frequentemente se encontram referências à competitividade da cidade e seu potencial para os negócios, assim como conceitos que se aproximam das ideias propagadas por Richard Florida, que traz a teoria dos três Ts: tecnologia, talento e tolerância como pilares para o desenvolvimento econômico.

A chamada classe criativa, tida por Florida como a nova classe a dominar a vida econômica, social e cultural desse século (Belanciano, 2008), se tornou nas últimas décadas, um público-alvo em muitos projetos, como o que vemos no Sapiens Parque. Para Florida, os locais que desejassem atrair essa classe criativa deveriam possuir oportunidades de emprego atraentes e terem uma infraestrutura bem equipada, com restaurantes, parques, arte e segurança, e essa atração estaria inserida em uma "batalha global pelos talentos" (Florida apud Belanciano, 2008).

Este projeto hegemônico para a cidade de Florianópolis avança em diferentes frentes, seja pela expansão urbana, rumo ao norte, com o Sapiens Parque, ou com as "revitalizações" e reestruturações urbanas do Centro Sapiens, proposta para o centro histórico da cidade.

No contexto neoliberal, as cidades são mais que o espaço onde as mercadorias são produzidas ou a infraestrutura onde os processos acontecem: a própria cidade é uma mercadoria, e, no processo de financeirização, temos maiores potenciais de negócios.

O padrão de financeirização que se define pela simbiose entre o mercado de capitais e as principais incorporadoras brasileiras atuou mais sobre a oferta do que sobre a demanda, colocando a dominância e a origem do processo numa estratégia definida entre o segmento imobiliário e os detentores da liquidez mundial. (Simoni-Santos \& Sanfelici, 2015: 16)

A cidade de Florianópolis, inserida de forma estratégica em rankings internacionais, parece fazer parte desse processo. Cabe ressaltar que as relações entre o mercado imobiliário florianopolitano e o mercado de capitais necessitariam de uma pesquisa de maior fôlego, mas elementos que apontam para essa relação aparecem nas estruturas de projetos na capital catarinense.

tecnológica da cidade. pbuscando ser a principal instância não-governamental a pensar e propor soluções para a cidade de Florianópolis. (FloripAmanhã, s/d) 


\section{SÃOPAULO15 17 LISBOA $25 \sim 26$ JUN 2020}

O projeto Sapiens Parque se conecta com o turismo de negócios em simbiose com o poder público e a iniciativa privada florianopolitana a partir das parcerias que o projeto mobiliza, envolvendo a infraestrutura hoteleira e de espaços de eventos e a atividade econômica relevante e internacionalizada, por meio das incubadoras e empresas de alta tecnologia, que atraem o público de mais alto poder aquisitivo almejado por esse setor do turismo. Não é mero acaso Florianópolis ser a $5^{\underline{a}}$ principal cidade brasileira no cenário do turismo de negócios e eventos: há um projeto estratégico de promoção das "belezas naturais da cidade", e, o Sapiens Parque faz uso disso ao se localizar justamente no eixo dos balneários mais valorizados do norte da ilha, a cerca de $1 \mathrm{~km}$ de praias como Canasvieiras e Cachoeira do Bom Jesus, $4 \mathrm{~km}$ da praia dos Ingleses e de Jurerê Internacional e $5 \mathrm{~km}$ do Santinho.

\section{Considerações Finais}

De acordo com os dados trazidos no presente artigo, pode se verificar que Florianópolis possui inserção no turismo de negócios não só nacional como internacional, tendo o projeto Sapiens Parque papel importante como vetor desse tipo de turismo, por meio de suas parcerias e centros de eventos, além da rede hoteleira e gastronômica da região.

Por meio do estudo de caso, com análise do projeto Sapiens Parque e publicações dos meios de comunicação, as hipóteses levantadas se mostraram pertinentes. Há um interesse especulativo em Florianópolis focado no turismo e na indústria de alta tecnologia, que tenta ocultar os conflitos da região, como a desigualdade de acesso à habitação adequada, o saneamento básico precário e os problemas de mobilidade.

Florianópolis possui diferentes atores com interesses conflitantes de projeto de cidade. O plano hegemônico, ilustrado na proposta do Sapiens Parque, exclui parcela da população, já que as desigualdades e as carências não aparecem nas peças publicitárias. A Florianópolis vendida aparece como um destino turístico da sustentabilidade, e a indústria de alta tecnologia, tida como uma indústria limpa, torna-se uma "boa aliada" nessa suposta vocação da cidade. O espaço urbano da cidade surge, portanto, cindido daqueles que lá moram e o produzem, pois este é tratado como objeto turístico, a ser consumido pelos novos sujeitos turistas, que consomem a cidade como produto, não mais somente pelas praias, mas também pelas oportunidades de negócios.

\section{Referências}

BELANCIANO, V. (2008). Richard Florida O guru do conceito das cidades criativas. https://www.publico.pt/2008/04/17/jornal/richard-florida-o-guru-do-conceito-das-cidades-criativas-257409 (consulta: 07/03/2020)

CARIONI, L. (2017). O que é um parque tecnológico? https://certi.org.br/blog/parque-tecnologico/ (consulta: 07/03/2020)

CARLOS, A. F. A. (2007). O lugar no/do mundo. São Paulo: FFLCH.

CORRÊA, M. K., \& PIERUCCINI, M. A. A. (2017). Construção de uma Vocação Turística para o Município de Florianópolis. Revista Eletrônica Ciências da Administração e Turismo v.5, n.1, 23 - 41.

CRUZ, R. C. A. (2007). Geografias do turismo: de lugares a pseudo-lugares. São Paulo: Roca. 


\section{SÃO PAULO15 $\sim 17 \cdot$ LISBOA $25 \sim 26$ JUN 2020 \\ Seminário Internacional de \\ Seminario Internacional de Investigação em Urbanismo

FERREIRA, L. B. (2010). Estratégias de segmentação da hotelaria para o turismo de negócios: um estudo em São Luís (MA). São Paulo: Universidade de São Paulo.

FERREIRA, V. M. S. (2017). A Rede de Cidades Criativas da Unesco: uma perspectiva das cidades brasileiras. Goiânia: Universidade Federal de Goiás.

FloripAmanhã. (2016). Floripa 2030 - Agenda Estratégica de Desenvolvimento Sustentável de Florianópolis na Região. Florianópolis.

FloripAmanhã. (s/d). Quem somos. http://floripamanha.org/quem-somos/ (consulta: 07/03/2020)

Fundación CEPA. (2017). Antecedentes 2017. La Plata.

HOST\&TRAVEL. (2018). CLUSTER é estratégia para a competitividade. http://revistahost.uol.com.br/tendencia/cluster-e-estrategia-para-a-competitividade-4.html (consulta: 07/03/2020)

Instituto Brasileiro de Geografia e Estatística. (2017). Pesquisa de Serviços de Hospedagem 2016. Rio de Janeiro.

Instituto Brasileiro de Geografia e Estatística. (2019a).Portal Cidades@. https://www.ibge.gov.br/cidades-eestados/sc/florianopolis.html (consulta: 12/02/2020)

Instituto Brasileiro de Geografia e Estatística. (2019b).Portal Cidades@. https://www.ibge.gov.br/cidades-eestados. html?view=municipio, (consulta: 19/02/2020)

International Congress and Convention Association. (2019). 2018 ICCA Statistics and Country and City Rankings - Public Abstract. Amsterdam.

KRONENBERGER, B. C., \& SABOYA, R. T. (2019). Entre a servidão e a beira-mar: um estudo configuracional da segregação socioespacial na Área Conurbada de Florianópolis (ACF), Brasil. urbe, Revista Brasileira de Gestão Urbana, 11, e20170227. https://doi.org/10.1590/2175-3369.011.e20170227

LENZI, M. H. (2016). A invenção de Florianópolis como cidade turística: discursos, paisagens e relações de poder. São Paulo: Universidade de São Paulo.

LUCHIARI, M. T. D. P. (1998). Urbanização turística: um novo nexo entre o lugar e o mundo. In: LIMA, L. C. Da cidade ao campo: a diversidade do saber-fazer turístico. Fortaleza: UECE.

Ministério do Turismo. (9 de dezembro de 2015). Portaria no 205. Brasília.

Ministério do Turismo. (2018). Plano Nacional de Turismo 2018-2022. Brasília.

Ministério do Turismo. (2019a). Categorização 2019/2021 do Programa de Regionalização do Turismo Brasileiro.

Brasília.

http://www.regionalizacao.turismo.gov.br/index.php?option=com_content\&view=article\&id=89\&/temid=272 (consulta: 26/02/2020)

Ministério do Turismo. (2019b). Categorização dos Municípios das Regiões Turísticas do Mapa do Turismo Brasileiro - Perguntas e Respostas. Brasília. 


\section{SÃO PAULO15 17 LISBOA $25 \sim 26$ JUN 2020}

OLIVEIRA, A. P. (2011). A história do turismo em Florianópolis: narrada por quem a vivenciou (1950-2010). Florianópolis: PalavraCom.

SÁ, M. F. (2004). Processo de Avaliação de Impactos Ambientais (AIA) do Empreendimento Sapiens Parque. Florianópolis: Universidade Federal de Santa Catarina.

Santa Catarina. (26 de janeiro de 2010). Lei Complementar nº 495. Florianópolis.

Sapiens Parque. (2018). Folder institucional. http://www.sapiensparque.com.br/wpcontent/uploads/2018/04/sapiens-parque_folder-2018.pdf (consulta: 07/03/2020)

Sapiens Parque. (31 de maio de 2019). O Sapiens Parque é o local ideal para receber empresas, projetos, institutos de Pesquisa e Desenvolvimento e iniciativas que buscam Facebook. https://www.facebook.com/SapiensParque/photos/a.1750413625173232/2311172232430699/?type=3\&theate r (consulta: 07/03/2020).

Secretaria do Estado da Fazenda. (2012). Estatísticas e Indicadores - Municípios. Governo de Santa Catarina. http://www.sef.sc.gov.br/transparencia/relatorio/31/Estat\%C3\%ADsticas_e_Indicadores__Munic\%C3\%ADpios (consulta: 19/02/2020)

SILVA, B. F. (2011). O Projeto Sapiens Parque: impactos socioeconômicos e ambientais em Florianópolis. Cadernos Metrópole, São Paulo, v. 13, n. 25.

SIMONI-SANTOS, C., \& SANFELICI, D. (2015). Caminhos da produção financeirizada do espaço urbano: a versão brasileira como contraponto a um modelo. Revista Cidades, São Paulo, v.12, n. 20.

SUGAI, M. I. (2015). Segregação silenciosa: investimentos públicos e dinâmica socioespacial na área conurbada de Florianópolis (1970-2000). Florianópolis: Ed. da UFSC.

VAINER, C. (2000). Pátria, empresa e mercadoria: notas sobre a estratégia discursiva do planejamento estratégico urbano. In: ARANTES, O., VAINER, C., \& MARICATO, E. A cidade do pensamento único: desmanchando consensos. Petrópolis: Vozes.

VÁLIO, M. I. L. (2004). Turismo de Negócios ou Negócios de Turismo? Revista Turismo. https://www.revistaturismo.com.br/artigos/turneg.html (consulta: 23/02/2020)

VIA. (2016). Sapiens Parque. http://via.ufsc.br/sapiens-parque/ (consulta: 07/03/2020)

VIA. (s/d). Sobre. http://via.ufsc.br/sobre/ (consulta: 08/03/2020) 